\title{
Specificity of HOX protein function depends on DNA-protein and protein-protein interactions, both mediated by the homeo domain
}

\author{
Vincenzo Zappavigna, Daniela Sartori, and Fulvio Mavilio ${ }^{1}$ \\ Laboratory of Gene Expression, Department of Biology and Technology (DIBIT), Istituto Scientifico H.S. Raffaele, \\ Milan, Italy
}

\begin{abstract}
Transcription of human HOX gene promoters in cultured cells is positively and negatively regulated by HOX proteins interacting with specific target sequences. The human HOXD9 protein activates transcription of the HOXD9 promoter by interacting with the HCR sequence and is antagonized by the HOXD8 protein. HOXD8 is not intrinsically a repressor, since it can activate transcription on different targets. Complete or partial HOXD8/HOXD9 homeo domain swapping indicates that the ability to recognize, and activate transcription from, the HCR target in vivo depends on the amino terminus and helix 1 of the homeo domain. The inhibitory activity of HOXD8 is not affected by deletion of the homeo domain helix 2/3 region, whereas it requires the amino terminus/helix 1 region and an additional, effector domain located at the protein amino-terminal end. This activity is therefore DNA-binding independent, and possibly mediated by protein-protein interactions. Affinity chromatography experiments show that the homeo domain amino terminus/helix 1 region is able to mediate direct interactions between HOX proteins in solution. These data indicate that specificity of HOX protein function in vivo depends on both DNA-protein and protein-protein interactions, mediated by the same sub region of the homeo domain.
\end{abstract}

[Key Words: Homeo box; homeo domain; transcriptional regulation; DNA-protein interaction; protein-protein interaction]

Received August 26, 1993; revised version accepted January 13, 1994.

Vertebrate homeo box-containing (Hox) genes, homologous to the Drosophila homeotic selector (HOM) genes, are organized in four related, unlinked clusters derived by duplication from a putative, ancestral Hox complex (Schubert et al. 1993). Expression of Hox genes is developmentally regulated and regionally restricted into partially overlapping expression domains in the paraxial mesoderm, the neuroectoderm, and the limbs (for review, see Gruss and Kessel 1991; Duboule 1992; McGinnis and Krummlauf 1992; Krumlauf 1993). This expression pattern suggests the existence of a Hox "code" specifying the identity of different regions or segments of the body, whereby progressively more posterior structures are defined by the activation of progressively more $5^{\prime}$ Hox genes in all four clusters (Hunt and Krumlauf 1991; Kessel and Gruss 1991). The molecular mechanisms by which this putative code is translated into positional specification are still largely unknown.

Hox proteins belong to a large family of transcription factors whose DNA-binding domain, the homeo domain, is structurally related to the helix-turn-helix motif

\footnotetext{
${ }^{1}$ Corresponding author.
}

common to several prokaryotic regulatory proteins (Laughon and Scott 1984; Gehring et al. 1990). Consistently, Hox proteins have been shown to bind DNA in vitro (Fainsod et al. 1986; Odenwald et al. 1989; Sasaki et al. 1990) and to regulate transcription through specific target sequences in cell culture (Zappavigna et al. 1991; Arcioni et al. 1992; Jones et al. 1992; Pöpperl and Feathersone 1992; Jones et al. 1993). The homeo domain and immediate flanking regions in both Hox and HOM proteins play a crucial role in DNA sequence recognition and binding in vitro (Desplan et al. 1988; Hoey and Levine 1988; Müller et al. 1988), and, at least in the case of HOM proteins, in the determination of the functional specificity in vivo (Kuziora and McGinnis 1989; Kuziora and McGinnis 1991). However, because all known Hox and HOM proteins have similar, if not identical, DNAbinding specificity in vitro /for review, see Hayashi and Scott 1990), they are unlikely to achieve their specificity of action in vivo only on the basis of DNA-protein interaction. The homeo domain DNA-binding and highaffinity target recognition functions have been shown to be neither sufficient nor absolutely required for the biological activity of HOM proteins, both in vivo and in cell culture (Fitzpatrick et al. 1992; Ananthan et al. 1993; 
Schier and Gehring 1993). Therefore, protein-protein interactions between different HOM (or Hox) proteins, or between these proteins and other components of the transcriptional machinery, could be critical factors in the regulation of $\mathrm{HOM} / \mathrm{Hox}$ functional specificity $(\mathrm{Ha}$ yashi and Scott 1990; McGinnis and Krumlauf 1992). In the case of other homeo domain-containing proteins, protein-protein interactions do play a role in enhancing DNA-binding specificity and/or regulating their functions (see Manak and Scott 1993), the best characterized examples being the yeast MAT (Smith and Johnson 1992) and the POU (Stern et al. 1989; Treacy et al. 1992; Verrijzer et al. 1992) transcription factors. So far, however, products of the HOM/Hox family genes were not known to establish protein-protein interactions among themselves and/or with other factors, even though such interactions have been postulated in several cases in order to explain their mechanism of action (Jaynes and $\mathrm{O}^{\prime} \mathrm{Far}-$ rell 1988; Han et al. 1989; Jaynes and O'Farrel 1991; Fitzpatrick et al. 1992; Ananthan et al. 1993; FurukuboTokunaga et al. 1993; Schier and Gehring 1993).

We and others had reported previously the existence of auto- and cross-regulatory interactions between mammalian Hox proteins and Hox gene regulatory elements, at least in cell culture (Zappavigna et al. 1991; Arcioni et al. 1992; Pöpperl and Featherstone 1992). In particular, the products of the human HOXD9 (HOX4C or Hox-4.4 according to the old nomenclature) and the immediately 5' HOXD10 (HOX4D or Hox-4.5) genes were shown to activate transcription of the HOXD9 promoter by binding to an evolutionary conserved, 100 -bp upstream element, termed HOX cross-talk region (HCR). The product of the immediately 3' gene HOXD8 (HOX4E or Hox-4.3) showed no activity on the HCR target but was able to antagonize the activating function of HOXD9 and HOXD10 in a cotransfection assay (Zappavigna et al. 1991). Whether these interactions take place and have any role in regulating HOX gene expression patterns in embryos is still to be established. Nevertheless, cross regulation in transfected cells provides a very convenient model for analyzing the DNA-binding requirements and functional properties of Hox proteins in vivo. In this report we show that specific target recognition by HOXD8 and HOXD9 in vivo is determined by the amino terminus and helix 1 of the homeo domain. The HOXD8 transcriptional inhibitory function is not dependent on DNA binding, and requires both the presence of the homeo domain amino terminus/helix 1 and the activity of an amino-terminal effector domain. We show that the amino terminus/helix 1 sub region of the Hox homeo domain is able to mediate protein-protein interactions between Hox proteins.

\section{Results \\ Specificity of target recognition by HOXD 8 in vivo is determined by the amino terminus/helix 1 region of the homeo domain}

The HOXD9 and HOXD8 proteins were expressed in the
SV40 promoter-based constructs $\mathrm{pD} 9$ and $\mathrm{pD} 8$, respectively (nos. 1 and 2 in Fig. 1). In a transient cotransfection assay in NIH-3T3 cells, HOXD9 was able to activate transcription from the regulatory sequence HCR fused to the -81 herpes simplex virus-thymidine kinase (HSVTK) promoter in the pTHCR luciferase (luc) reporter construct (Fig. 1), whereas HOXD8 was inactive (Zappavigna et al. 1991; Fig. 2A). To test whether HOXD8 is intrinsically unable to activate transcription, the amino-terminal 176 amino acids were replaced by the acidic activation domain of the yeast transcription factor GAL4 (amino acids 149-196) (Gill and Ptashne 1987) in the pGALD8 expressor construct (no. 3 in Fig. 1). Cotransfection of pGALD8 with pTHCR resulted in no significant stimulation of luc activity (Fig. 2A), indicating that the lack of activating function in the HOXD8 protein is not attributable to the absence of an efficient activation domain. In parallel, pD8 and pGALD8 were cotransfected with the reporter construct pTCBS, in which a multimerized form of a homeo domain consensus-binding sequence (CBS; see Materials and methods) was linked to the -109 HSV-TK promoter (Fig. 1). This construct is trans-activated in the cotransfection assay by a large number of HOX proteins (not shown), including HOXD9 (Fig. 2B). The activity of pTCBS increased six- to eight-fold when cotransfected with pD8 or pGALD8 (Fig. $2 \mathrm{~B}$ ), showing that HOXD8 is able to activate transcription from an appropriate target in cell culture.

These results suggest that the HOXD8 protein is unable to recognize the HCR target in vivo, although it can bind to the same sequence in vitro (Zappavigna et al. 1991). To test this hypothesis, we generated two chimeric constructs representing homeo domain swaps between the HOXD8 and HOXD9 proteins. In the pD8swD9 expressor construct (no. 4 in Fig. 1), 66 amino acids of the HOXD8 protein, 1 amino acid upstream to 5 amino acids downstream of the homeo domain, were replaced by the corresponding residues of the HOXD9 homeo domain (see Fig. 3). The pD9swD8 construct contained the reciprocal substitution (no. 5 in Fig. 1). As shown in Figure 2A, the homeo domain swap was sufficient to confer to HOXD8 the ability to recognize HCR as a target sequence, whereas it caused an almost complete loss of HOXD9 activity on the same target. Both D8swD9 and D9swD8 proteins, like their "wild-type" counterparts D8 and D9, were able to trans-activate the control pTCBS reporter construct (Fig. 2B).

To restrict the region of the HOXD9 homeo domain responsible for the recognition of HCR in vivo, we replaced the amino terminus and helix 1 of the HOXD8 homeo domain (amino acids 194-214) with the corresponding region of HOXD9 (amino acids 274-294) in the pD8H1D9 construct (no. 6 in Fig. 1). As shown in Figure 3 , this region contains half of the amino acid differences between the HOXD8 and HOXD9 homeo domains. Cotransfection of pD8H1D9 resulted in trans-activation of pTHCR to an extent comparable with that obtained with the wild-type HOXD9 protein (pD9) or the HOXD8 chimera containing the entire HOXD9 homeo domain (pD8swD9) (Fig. 2A). These results show that the amino 
Zappavigna et al.

\section{PROTEIN-EXPRESSION PLASMIDS}

Construct
no.

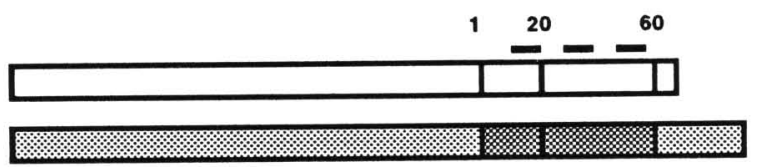

$\begin{array}{ll}\begin{array}{l}\text { Activation } \\ \text { of reporter: }\end{array} & \begin{array}{l}\text { Repression } \\ \text { of HOXD9 } \\ \text { activation: }\end{array} \\ \text { HCR CBS } & \end{array}$

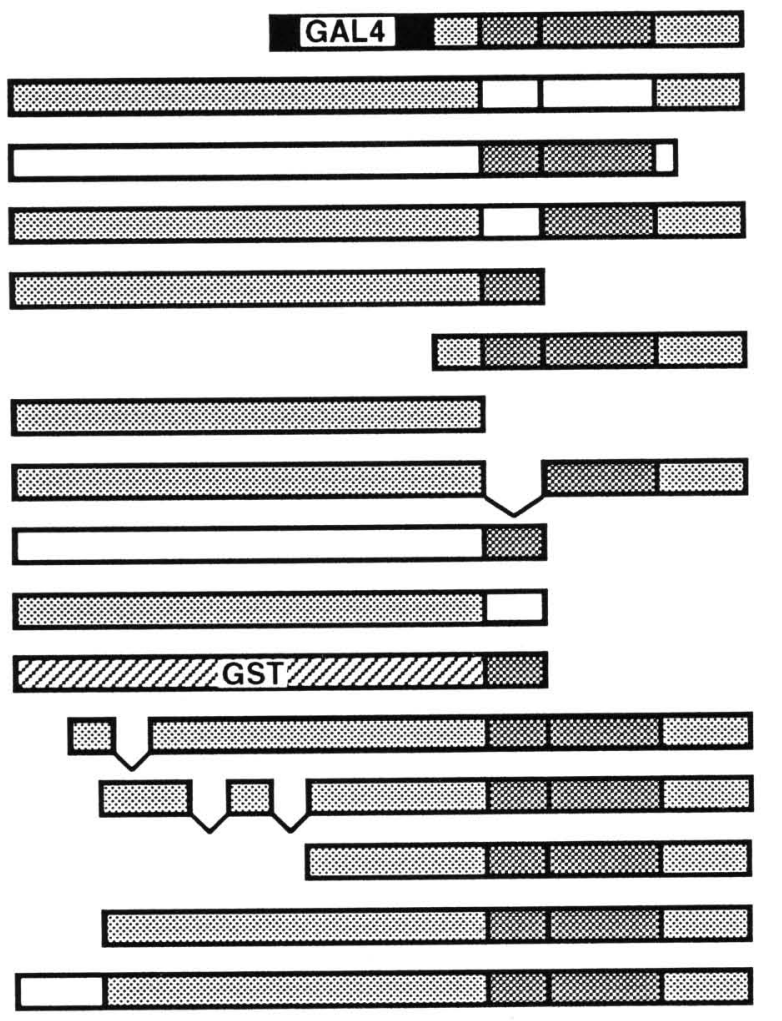

$\begin{array}{llll}+ & + & \\ - & + & \text { Yes } \\ - & + & \text { No } \\ + & + & \text { n.d. } \\ - & + & \text { No } \\ + & + & \text { n.d. } \\ - & - & \text { Yes } \\ - & - & \text { No } \\ - & - & \text { No } \\ - & - & \text { No } \\ - & - & \text { No } \\ - & - & \text { Yes } \\ - & - & \text { No } \\ - & + & \text { Yes } \\ - & + & \text { Yes } \\ - & - & \text { No } \\ - & + & \text { No } \\ - & + & \text { No }\end{array}$

REPORTER PLASMIDS

PTHCR

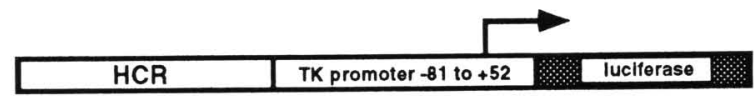

pTCBS

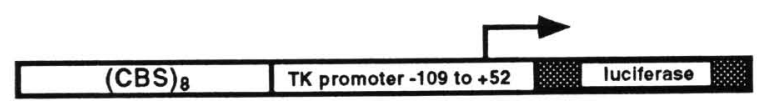

Figure 1. Protein-expression and reporter constructs used in cotransfection experiments. Complete coding sequences of the HOXD9 (white) and HOX8 (shaded) genes are indicated. The regions of HOXD9 and HOXD8 involved in the chimerical and/or mutant versions of both proteins (amino terminus, homeo domain, carboxyl terminus) are indicated by separate boxes. The homeo domains (darker in HOXD8) are further subdivided in two boxes, representing the amino terminus/helix 1 (amino acids 1-20) and helices 2-4 (amino acids 20-60). Helices 1,2 , and 3/4 are indicated schematically by small black bars on top of construct no. 1. (正) The acidic activator domain of the yeast GAL4 transcription factor; a hatched box indicates the coding sequence of the GST gene. The splicing signs indicate internal deletions in the HOXD8 amino terminus and homeo domain. In the reporter plasmids, the HOXD9 upstream control element (HCR), and an 8-mer repeat of a Hox CBS are indicated. The activity of each expression construct in trans-activating the pTHCR or pTCBS reporter is indicated by + and - signs (right), together with the ability to inhibit the HOXD9-induced trans-activation of pTHCR. (n.d.) Not determined. 
A

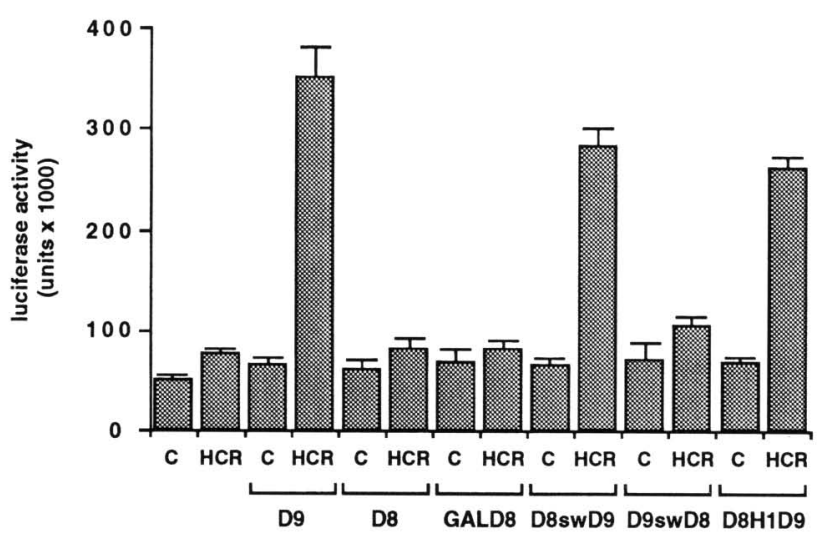

B

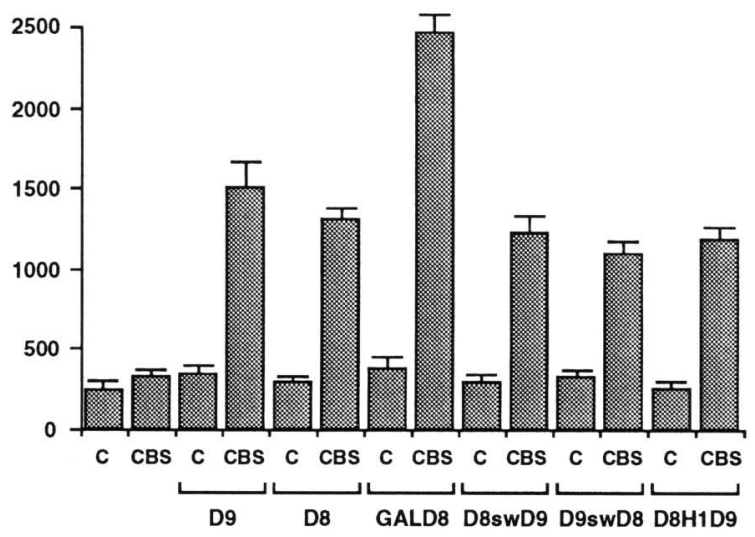

Figure 2. Analysis of the activity of HOXD9 and HOXD8 on the HCR $(A)$ and CBS $(B)$ target sequences by transient cotransfection assay in NIH-3T3 cells. Five micrograms of pSG5-based expression constructs for HOXD9 (D9), HOXD8 (D8), an aminoterminal fusion between HOXD8 and the acidic activator domain of GAL4 (GALD8, no. 3 in Fig. 1), two hybrid proteins originated by homeo domain swapping (D8swD9 and D9swD8, nos. 4 and 5 in Fig. 1), and a hybrid HOXD8 protein containing the amino terminus/helix 1 of the HOXD9 homeo domain (D8HID9, no. 6 in Fig. 1), were cotransfected with $10 \mu \mathrm{g}$ of pT81luc $(C)$ or pTHCR (HCR) $(A)$, or $5 \mu \mathrm{g}$ of pT109luc $(C)$ or pTCBS $(C B S)(B)$ reporter constructs, and $1 \mu \mathrm{g}$ of the pRSV $\beta$ gal plasmid as an internal standard. Luciferase activity is expressed in arbitrary light units. Bars, the mean \pm S.E.M. of at least five independent experiments.

terminus/helix 1 sub region of the HOXD9 homeo domain is sufficient to allow specific recognition of the HCR target in vivo.

\section{HOXD8 inhibits the activating function of HOXD9 on the HCR target}

Cotransfection of increasing amounts of $\mathrm{pD} 8$ (from equimolar to 2:1 excess) with pD9 and pTHCR resulted in progressive inhibition of the reporter gene trans-activation induced by HOXD9 (Fig. 4). This inhibition is un- likely to be attributable to a squelching effect, as transfection of excess pD8 caused no inhibition of the HOXD8-mediated trans-activation of the pTCBS reporter, nor of the activity of an unrelated transcription factor on its target, like that of the retinoic acid receptor $\beta$ (RAR $\beta$ ) on the retinoic acid responsive element (RARE)-TK-luc reporter construct (data not shown). Cotransfection of pD8 $\mathrm{H} 2 / 3$ (no. 7 in Fig. 1), which expresses a HOXD8 deletion mutant lacking the homeo domain DNA-binding helix $2 / 3$ region and the protein carboxyl terminus (amino acids 214-289, see Fig. 3), caused the same dose-dependent antagonistic effect observed for pD8 (Fig. 4), indicating that the HOXD8 inhibitory activity does not require DNA binding. Conversely, cotransfection of pD8HD (no. 8 in Fig. 1), expressing only the homeo domain and carboxyl terminus of HOXD8 (amino acids 194-289, see Fig. 3), had no effect on the HOXD9-induced trans-activation of pTHCR (Fig. 4). These results indicate that transcriptional inhibition by HOXD8 is not attributable to competition for binding to the HCR sequence. Production and correct nuclear targeting of the D8HD and D $8 \mathrm{H} 2 / 3$ mutants was checked by immunoblotting and immunofluorescence analysis (see Materials and methods, data not shown).

\section{The HOXD8 inhibitory activity requires the presence of the amino terminus/helix 1 region of the homeo domain}

To identify the region(s) of the HOXD8 protein required for the inhibitory function, two additional constructs were generated which express deletion mutants lacking either the whole homeo domain $\mid \mathrm{pD} 8 \Delta \mathrm{HD}$, no. 9 in Fig. 1, encoding the amino-terminal portion of HOXD8 from amino acids 1-193, see Fig. 3), or only the amino terminus and helix 1 (pD8 $\Delta \mathrm{H} 1$, no. 10 in Fig. 1, deleted in the region corresponding to amino acids 196-214, see Fig. 3). Cotransfection of either $\mathrm{pD} 8 \Delta \mathrm{HD}$ or $\mathrm{pD} 8 \Delta \mathrm{Hl}$ had no effect on the HOXD9-mediated trans-activation of pTHCR (Fig. 4), showing that the 19-amino acid region that contains the amino terminus and helix 1 of the HOXD8 homeo domain is necessary for the inhibitory activity. Production and nuclear targeting of the $\mathrm{D} 8 \Delta \mathrm{HD}$ and $\mathrm{D} 8 \Delta \mathrm{Hl}$ deletion mutants were checked as described above (not shown).

Interestingly, expression of the HOXD8 mutant lacking the DNA-binding region of the homeo domain (pD8 $\mathrm{H}$ H2/3, no. 7 in Fig. 1) caused inhibition of the wildtype HOXD8 activity on the pTCBS reporter construct. This suggests that the $\mathrm{D} 8 \Delta \mathrm{H} 2 / 3$ protein, unable to bind DNA and therefore to activate transcription from the pTCBS reporter, behaves as a dominant-negative mutant with respect to the HOXD8/CBS interaction. Excess HOXD8 protein caused no inhibition of its own activity on the CBS target (not shown), suggesting that the inhibitory activity of HOXD8 is alternative to target recognition, and unmasked by the deletion of part of its DNAbinding domain. 
Zappavigna et al.

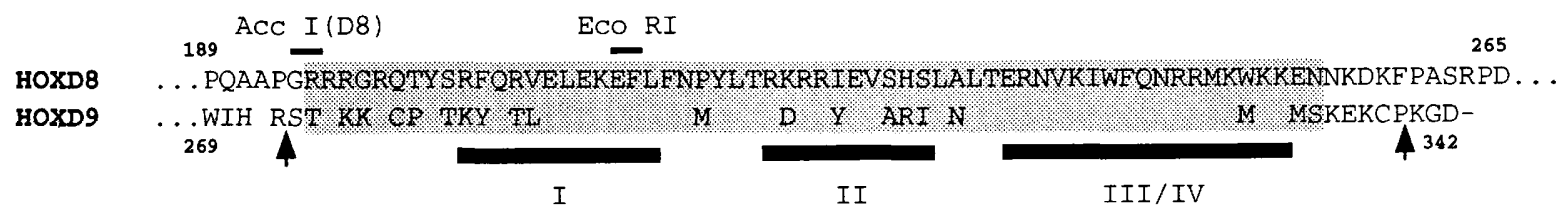

Figure 3. Alignment of the HOXD8 and HOXD9 homeo domain (shaded) and flanking regions. Amino acid residues are indicated according to the one-letter code. Blank spaces indicate amino acid identity. The numbers indicate the positions of amino acid residues within each protein. Black bars indicate the first, second, and third/fourth $\alpha$-helical regions within the homeo domains. The limits of the regions swapped between HOXD8 and HOXD9 in the pD8swD9 and pD9swD8 expression constructs (nos. 4 and 5 in Fig. 1) are indicated by arrows. Also indicated is the location (small bars) of the AccI restriction site in HOXD8 and the EcoRI site in both HOXD8 and HOXD9 DNA sequence, used for construction of the mutants (see Materials and methods).

The amino terminus and helix 1 of the HOXD8 homeo domain mediate protein-protein interactions between HOXD8 and HOXD9

The experiments described above showed that the inhibitory activity of HOXD8 is DNA binding independent and requires the presence of the amino terminus/helix 1 sub region of the homeo domain. To provide evidence for a possible role of this sub region in mediating proteinprotein interactions between HOXD8 and HOXD9, we used a protein-protein affinity chromatography technique. A fusion protein between the HOXD9 homeo domain (amino acids 270-342, see Fig. 3) and the carboxyl terminus of the glutathione-S-transferase (GST) enzyme was expressed in bacteria, purified, and immobilized onto glutathione-Sepharose resin. The HOXD8 protein and the deletion mutants $\mathrm{D} 8 \Delta \mathrm{HD}$ and $\mathrm{D} 8 \Delta \mathrm{H} 2 / 3$ were translated and ${ }^{35} \mathrm{~S}$-labeled in vitro, batch-adsorbed to the GST-HOXD9-homeo domain resin (GST-D9HD in Fig. $5 \mathrm{~A}$ ) or to a GST control resin (GST in Fig. 5A), and then eluted and analyzed by SDS-PAGE. As shown in Figure $5 \mathrm{~A}$, the full-length HOXD8 protein (D8) and the $\mathrm{D} 8 \Delta \mathrm{H} 2 / 3$ mutant lacking the homeo domain helix $2 / 3$ region were specifically retained by the GST-D9HD resin, whereas the D8 $\Delta \mathrm{HD}$ mutant lacking the entire homeo domain was not retained. These data show that HOXD8 and HOXD9 are able to establish protein-protein contacts in solution in the absence of DNA through their homeo domains and that the amino terminus/helix 1 of the HOXD8 homeo domain is necessary for this interaction. The in vitro-translated HOXD9 protein was able to associate as efficiently as HOXD8 to the GSTD9HD resin (Fig. 5A), indicating that the HOXD9 homeo domain has a potential ability to establish both heterophylic and homophylic interactions in solution.

A GST fusion protein containing only the amino terminus/helix 1 of the HOXD9 homeo domain lamino acids 270-294, see Fig. 3) was then generated (GST-D9H1 in Fig. 5B), coupled to glutathione-Sepharose, and used in protein-protein affinity chromatography experiments. As shown in Figure 5B, D8 and the D8DH2/3 mutant associated specifically with the GST-D9H1 resin, whereas the D8 $8 \mathrm{HD}$ mutant failed to bind. Binding of HOXD8 to the GST-D9H1 resin was specifically competed by a $\sim 20$-fold excess of unlabeled protein (D8c) produced in bacteria (Fig. 5B). In a reciprocal experiment, the in vitro-translated HOXD9 protein was specifically retained by a resin coupled to a fusion between GST and the amino terminus/helix 1 (amino acids 194-214, see Fig. 3) of the HOXD8 homeo domain (GST-D8H1, Fig. $5 \mathrm{~B}$, right). On average, $10-25 \%$ of the labeled, input proteins were retained by the GST fusion resins. These results indicate that the HOXD8/HOXD9 protein-protein interaction in solution is mediated by the amino terminus/helix 1 sub region of both homeo domains.

\section{Binding of HOXD9 to HCR in vitro is not affected by $H O X D 8$}

Because HOXD8 and HOXD9 are able to establish pro-

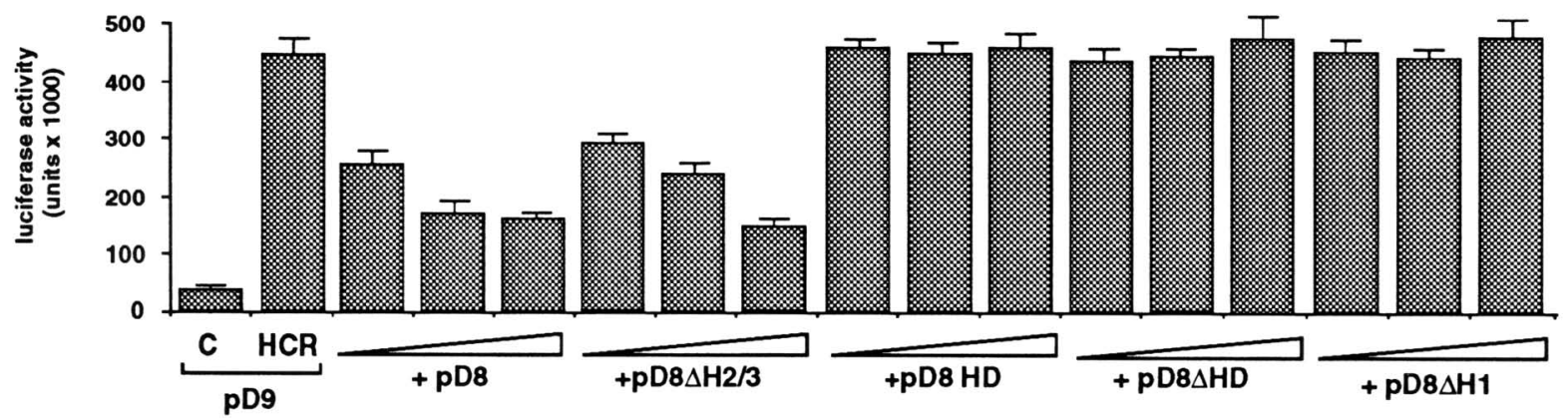

Figure 4. The amino terminus/helix 1 region of the HOXD8 homeo domain is necessary for antagonizing the activity of HOXD9 on the pTHCR reporter. NIH-3T3 cells were cotransfected with $10 \mu \mathrm{g}$ of either pT81luc (C) or pTHCR (HCR) and $5 \mu \mathrm{g}$ of pD9 (first two bars in each panel), or with $10 \mu \mathrm{g}$ of pTHCR, $5 \mu \mathrm{g}$ of $\mathrm{pD}$, and increasing amounts $(1,5$, and $10 \mu \mathrm{g})$ of expressor constructs for either HOXD8 (pD8) or four different HOXD8 deletion mutants (see Fig. 1 for identification). The total amount of transfected DNA was kept constant by complementation with up to $10 \mu \mathrm{g}$ of the pSG5 plasmid. One microgram of pRSVBgal was added as an internal standard. Luciferase activity is expressed in arbitrary light units. Bars, the mean \pm S.E.M. of at least six independent experiments. 

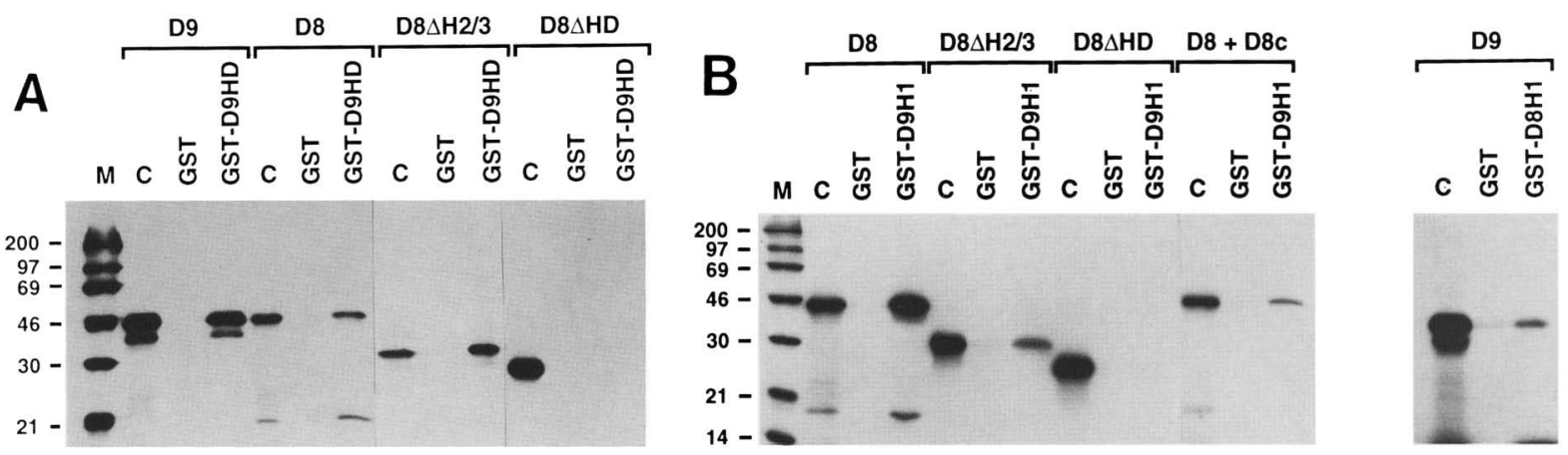

Figure 5. Protein-protein interaction in solution between HOXD8 and HOXD9, as analyzed by protein-protein affinity chromatography and SDS-PAGE. (A) Glutathione-Sepharose coupled to GST-HOXD9 homeo domain fusion (GST-D9HD) was batch-adsorbed to ${ }^{35}$ S-labeled full-length HOXD9 (D9) or HOXD8 proteins (D8), or HOXD8 deletion mutants lacking the homeo domain helix $2 / 3$ $(\mathrm{D} 8 \Delta \mathrm{H} 2 / 3)$ or the entire homeo domain $\langle\mathrm{D} 8 \Delta \mathrm{HD})$. The same proteins were batch-adsorbed to a control resin coupled to GST only. One microliter of each in vitro translation reaction containing the labeled, input proteins $(10 \mu l)$ was loaded as a control $(C)$. $(B)$ The same experiment was carried out with a GST fusion containing only the amino terminus/helix 1 of the HOXD9 or the HOXD8 homeo domains (GST-D9H1 and GST-D8H1, respectively). The binding reaction was carried out also in the presence of a 20 -fold excess of unlabeled, bacterially made HOXD8 protein (D8 + D8c). Relative molecular mass standards (M) are in kilodaltons.

tein-protein interactions in the absence of DNA, we tested whether such interactions may affect the binding of HOXD9 to the HCR target. The full-length HOXD8 and HOXD9 proteins were expressed in NIH-3T3 cells fused to an amino-terminal, 6-histidine tag and partially purified by affinity chromatography under native conditions (see Materials and methods). The amount of active protein was titrated in both preparations by in vitro binding to a 32-bp oligonucleotide containing two HOX-binding sites located in the $5^{\prime}$ part of HCR (see Materials and methods), followed by a gel-shift assay (Fig. 6A). A fixed amount of active HOXD9 protein was then mixed with increasing amounts of HOXD8, incubated with the HCR-derived oligonucleotide and then analyzed by the same assay. The concentration of HOXD8 and HOXD9 in the binding reactions was in the same order of magnitude as in the GST-affinity-chromatography experiments (see Materials and methods), potentially allowing the establishment of protein-protein interactions. As shown in Figure 6A, the two proteins bound independently to DNA, and the presence of excess HOXD8 in the binding reaction caused neither significant decrease in the binding of HOXD9 to the oligonucleotide, nor the formation of new DNA-protein complexes.

We also tested whether the presence of HOXD8 affects the dissociation rate of HOXD9 from the HCR target. The HOXD9 protein was allowed to bind to equilibrium to the labeled oligonucleotide, in the absence or in the presence of an equimolar amount of HOXD8. The DNAprotein complexes were then challenged by addition of a 250-fold excess of unlabeled oligonucleotide and loaded on a running gel after short time intervals. As shown in Figure 6B, the off-rate of HOXD9 from the target DNA was very rapid and was not significantly affected by the presence of HOXD8.

The inhibitory activity of HOXD8 requires an amino-terminal effector domain

As described above (Fig. 4), the D8HD mutant (no. 8 in
Fig. 1), containing the entire homeo domain and carboxyl terminus of HOXD8, had no inhibitory activity on HOXD9. This suggested that the homeo domain amino terminus/helix 1 region, although necessary, is not sufficient for the inhibition, which apparently requires the presence of an additional function located in the aminoterminal portion of the HOXD8 protein. To test whether the HOXD8 amino terminus is specifically required for the inhibitory function, we generated two expression constructs in which either the amino-terminal portion of HOXD9 (amino acids 1-273) or the GST protein were fused to the amino terminus/helix 1 region of the HOXD8 homeo domain (pD9swD8H1 and pGSTD8H1 respectively, nos. 11 and 13 in Fig. 1). Cotransfection of these two constructs, and of pGALD8 in which the HODXD8 amino terminus is replaced by the GAL4 activator domain (no. 3 in Fig. 1), resulted in no change in the HOXD9 activity on pTHCR (Fig. 7, and summary in Fig. 1). Conversely, an expressor construct in which the HOXD8 amino terminus (amino acids 1-193) was fused to the amino terminus/helix 1 of the HOXD9 homeo domain (pD8swD9H1, no. 12 in Fig. 1) showed the same inhibitory activity on HOXD9 (Fig. $7 \mathrm{~A}$ ) as the pD8 $\Delta \mathrm{H} 2 / 3$ construct (Fig. 4). This indicates that the inhibitory function of the amino terminus (the effector function) is specific for HOXD8, whereas the function of the homeo domain amino terminus/helix 1 region (the protein-protein interaction function/ can be exerted also by the corresponding region of the HOXD9 protein.

To narrow down the region in the HOXD8 amino terminus responsible for the inhibitory function, we generated a number of deletion mutants within this region. Internal deletions of a polyalanine repeat (amino acids 15-33, see Fig. 8), or of a histidine-proline- and a prolinerich repeat (amino acids 67-79 and 106-120, see Fig. 8), represented by the $\mathrm{pD} 8 \Delta \mathrm{RP} 1$ and $\mathrm{pD} 8 \Delta \mathrm{RP} 2 / 3$ construct, respectively (nos. 14 and 15 in Fig. 1), had no effect on the inhibitory activity (Fig. 7B). Moreover, cotransfection of an expression construct for the HOXC8 protein 

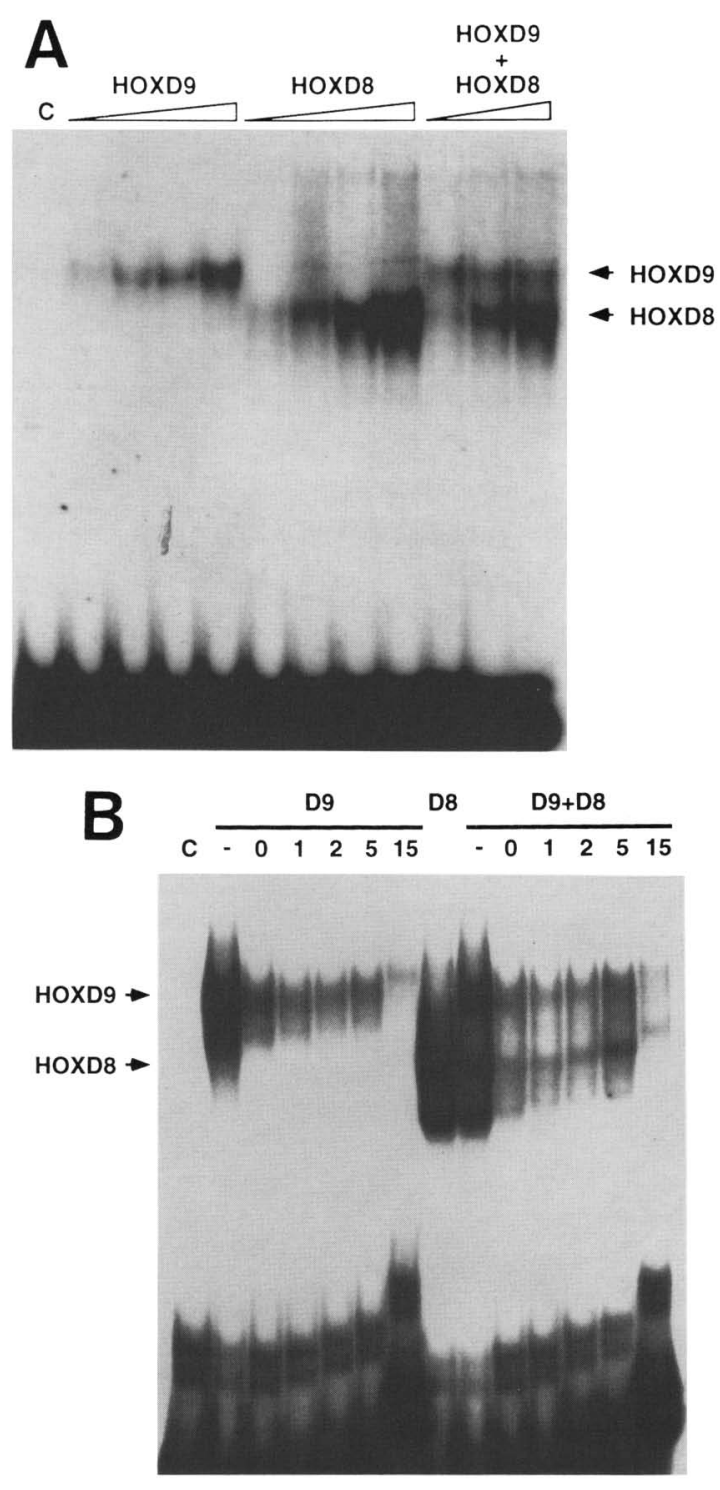

Figure 6. (A) Electrophoretic mobility shift assay of a 32-bp, double-stranded oligonucleotide containing two HOX-binding sites located in the $5^{\prime}$ region of the HCR target sequence (see Materials and methods), after binding to purified HOXD8 and HOXD9 proteins. Binding reactions contained increasing amounts of the $\operatorname{HOXD} 9(0.5,1,2$, and $4 \mu \mathrm{l})$ or $\operatorname{HOXD} 8(2,4,6$, and $8 \mu \mathrm{l})$ eluates, or a fixed amount of the HOXD9 $(2 \mu \mathrm{l})$ and increasing amounts of the $\operatorname{HOXD} 8(4,6$, and $8 \mu l)$ eluate (HOXD9 + HOXD8). (C) Control, free probe. The mobility of the HOXD8-DNA and HOXD9-DNA complexes is marked on the right. $(B)$ Dissociation rate of the HOXD9-DNA complex in the absence (D9) or in the presence (D9 + D8) of equimolar amounts of HOXD8. Binding reaction were challenged by a 250 -fold excess of unlabeled oligonucleotide. Aliquots were removed at the indicated times $(0-15 \mathrm{~min})$ and loaded on a running $4 \%$ polyacrylamide gel. The mobility of the HOXD8-DNA and HOXD9-DNA complexes is marked on the left.

(pC8), the product of the gene paralogous to HOXD8 on the HOXC cluster (Le Mouellic et al. 1988), had the same inhibitory effect as pD8 on HOXD9 activity (Fig. 7B and
4). HOXC8 is highly homologous to HOXD8 in the amino-terminal region, although it contains none of the three repeats (see Fig. 8), which are therefore not necessary for the inhibitory activity. Conversely, a deletion of the amino-terminal 117 residues, represented by the pD8 $\Delta(1-117)$ construct (no. 16 in Fig. 1), caused complete loss of the HOXD8 inhibitory activity (Fig. 7C). Interestingly, the $\mathrm{D} 8 \Delta(1-117)$ mutant was also unable to activate the pTCBS reporter construct (Fig. 7D), indicating that both the inhibition and the activation domains of HOXD8 are contained in the amino-terminal 117 residues. A deletion of the first 46 residues $[\mathrm{pD} 8 \Delta(1-46)$, no. 17 in Fig. 1] was instead unable to inhibit the HOXD9 activity (Fig. 7C) while it showed an activity comparable with that of the full-length protein on the pTCBS reporter (Fig. 7D). These results indicate that the HOXD8 inhibitory effector domain can be separated from the activation domain and is located in the amino-terminal 46 residues, the region of highest homology between the three proteins belonging to the paralogous group 8 /see Fig. 8). To strengthen this conclusion, the amino-terminal 46 residues of $\mathrm{HOXD} 8$ were swapped with the corresponding region of HOXD9, in the pD8NTD9 construct (no. 18 in Fig. 1). Cotransfection of this construct had no effect on the HOXD9 activity (Fig. 7C), confirming that the HOXD8 amino-terminal 46 residues are specifically required for the inhibitory function. The pD8NTD9 mutant was active on the pTCBS reporter (Fig. 7D), confirming that the HOXD8 activation domain is located between amino acids 46 and 117 .

\section{The HOXD8 homeo domain is able to establish protein-protein interactions with several members of the HOX gene family}

To test whether the ability to establish protein-protein interactions is unique to HOXD8 and HOXD9 or rather reflects a more general potential of the HOX homeo domain, we used the affinity-chromatography technique to test for interactions between the HOXD8 homeo domain and the products of other HOX genes belonging to different clusters and/or paralogous groups. The in vitrotranslated, ${ }^{35}$ S-labeled products of HOXB3, HOXC4, HOXC5, HOXC8, and HOXD10 genes were batch-adsorbed to the GST-D8HD resin or to a GST control resin. Retained proteins ranged between $10 \%$ and $30 \%$ of the total input. As shown in Figure 9, all tested proteins were able to associate specifically with the GST-D8HD resin, indicating that homeo domain-mediated proteinprotein interaction is possible between different members of the HOX gene family.

\section{Discussion}

Specificity of target recognition by Hox proteins in vivo depends on the amino terminus/helix 1 region of the homeo domain

A regulatory element located in the HOXD9 upstream genomic region (the HCR sequence), was reported previ- 
C
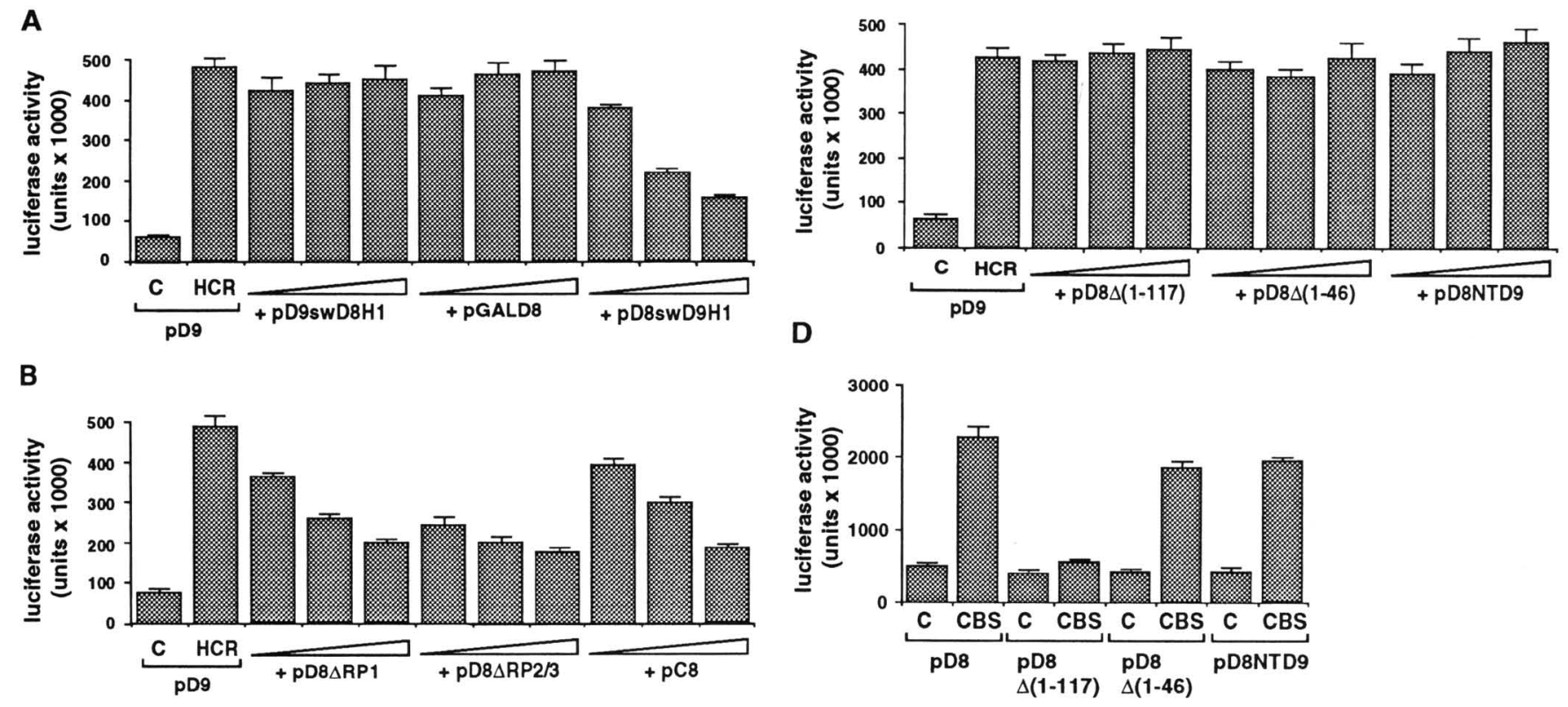

Figure 7. Characterization of the HOXD8 amino terminal effector domains. $(A-C)$ NIH-3T3 cells were cotransfected with $10 \mu g$ of either pT81luc (C) or pTHCR (HCR) and $5 \mu \mathrm{g}$ of pD9 (first two bars in each panel), or with $10 \mu \mathrm{g}$ of pTHCR, $5 \mu \mathrm{g}$ of pD9, and increasing amounts $(1,5$, and $10 \mu \mathrm{g})$ of expressor constructs for different HOXD8 amino-terminal deletion mutants or fusion proteins. $(D)$ Cells were transfected with $5 \mu \mathrm{g}$ of either pT109luc or pTCBS, and $5 \mu \mathrm{g}$ of pD8 or expressor constructs for two HOXD8 deletion mutants and a HOXD8-HOXD9 fusion protein. Identification of the expression constructs is given in Fig. 1. The total amount of transfected DNA was kept constant by complementation with up to $10 \mu \mathrm{g}$ of the pSG5 plasmid. One microgram of pRSV $\beta$ gal was added as an internal standard. Luciferase activity is expressed in arbitrary light units. Bars, mean \pm S.E.M. of at least five independent experiments.

ously to mediate both positive and negative regulation in response to Hox proteins. The HOXD9 and HOXD10 proteins are transcriptional activators of the HCR sequence in a transient transfection assay, whereas HOXD8 is inactive although it can bind HCR in an in vitro assay (Zappavigna et al. 1991). HOXD8 is nonetheless active on a different HOX gene promoter (Arcioni et al. 1992) or on a heterologous promoter linked to a multimerized Hox CBS (this paper). We show that homeo domain swapping between HOXD8 and HOXD9 is sufficient to transfer the target specificity to each other protein, indicating that specific target recognition in vivo depends almost entirely on the homeo domain structure. Therefore, this specificity cannot be predicted by in vitro binding studies, which are either unable to provide appropriate stringency conditions or lack additional/accessory factors favoring DNA-protein recognition in a cell context. The HOXD8 and HOXD9 homeo domains differ in 20 of 60 amino acids, 11 located in the amino terminus/helix 1 region, and 9 in the DNA-binding, helix $2 / 3$ segment (see Fig. 3). We show that swapping of the amino terminus/helix 1 region is sufficient to provide HOXD8 with the in vivo target specificity of HOXD9. In Drosophila embryos, much of the functional specificity of the Dfd, Ultrabithorax (Ubx), Antp and Sex combs reduced $(S c r$ ) homeo domains was reported to be conferred by the amino-terminal region, a flexible arm establishing contacts with the DNA minor groove, and particularly by the amino acids $1,4,6$, and 7 (Lin and McGinnis 1992; Furukubo-Tokunaga et al. 1993). These positions are occupied by different residues in the HOXD8 and HOXD9 homeo domains (Fig. 3). In particular, the $K$ residue at position 4 and the C-P residues at position 6-7 are invariant in all Hox homeo domains belonging to the $A b d B$-like paralogous groups 9, 10, and 11 , and characteristically different from the G and Q-T residues respectively conserved in the homeo domains belonging to the $A b d A / U b x / A n t p$-like groups 7 and 8 (see Mavilio 1993). We therefore suggest that these residues might play a role in the appropriate recognition of, and/or interaction with, the HCR target by the HOXD9 and HOXD10 homeo domains in vivo.

\section{The amino terminus/helix 1 region of the Hox homeo domain mediates protein-protein interactions}

As reported previously, the HOXD8 protein is able to inhibit the activating function of HOXD9 and HOXD10 on the HCR sequence in a cotransfection assay (Zappavigna et al. 1991). We now show that this activity is DNA binding independent and requires the same amino terminus/helix 1 region of the homeo domain that allows specific target recognition in vivo. Affinity chromatography experiments showed that this sub domain is a protein-protein contact interface, which can mediate direct interactions between Hox proteins in solution. It 


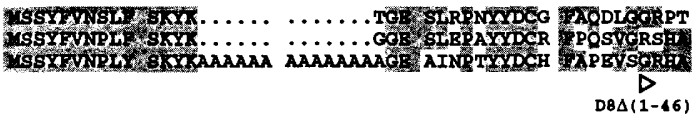

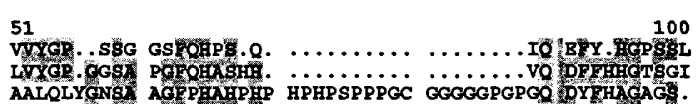
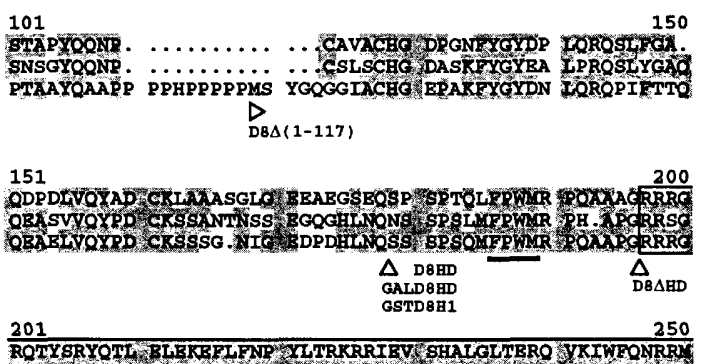
ROTYSRYOTH TRKE FIFT S Y LTRKRRIEV SHA TSLTERO YKIWFONRR

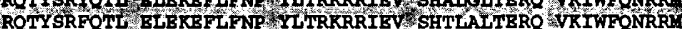
$\Delta$ $\triangle_{D B \Delta \mathrm{H} / 3}$

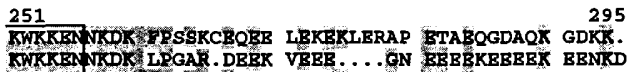
KWKKBA KKD K RASRPEAKD GDPKKBASEL EBDGAEGCPT N....

Figure 8. Best-fit alignment of the protein products of HOXD8 and the paralogous genes $\mathrm{HOXB} 8$ and $\mathrm{HOXC} 8$. Numbers indicate amino acid positions in the HOXD8 sequence. Conserved amino acids are indicated by shaded areas. The homeo domains are boxed. The evolutionary conserved FPWM peptide is underlined. Triangles indicate the beginning of HOXD8 sequences in the indicated fusion or deletion mutants. Right-pointed triangles indicate the beginning of the amino-terminal deletion in the pD8 $\Delta(1-46)$ construct, and the internal Met residue used as a translation start in the deletion mutant expressed by the $\mathrm{pD} 8 \Delta(1-117)$ construct.

can therefore be suggested that specificity in both target recognition and function of Hox proteins in vivo is determined through the establishment of protein-protein interactions, either among Hox proteins and/or between Hox proteins and other yet unknown cofactors. In the Drosophila system, mutants of the fushi tarazu (ftz) protein lacking the homeo domain DNA-binding region retain significant biological activity both in embryos and in cell culture, suggesting that protein-protein interactions may be required for at least some of the $\mathrm{ftz}$ functions (Fitzpatrick et al. 1992; Ananthan et al. 1993). Mutations in the gene extradenticle (exd) alter segmental identity without affecting the HOM gene expression patterns, most likely by affecting their target specificity in vivo (Peifer and Wieschaus 1990). It is noteworthy that the exd protein, containing a homeo domain distantly related to that of the HOM/Hox proteins, was reported to affect $U b x$ target specificity by interacting with its homeo domain (Rauskolb et al. 1993). Although it was not specifically addressed by these studies, protein-protein interactions mediated by the amino terminus/helix 1 region of the homeo domain(s) might play a significant role in the case of both $\mathrm{ftz}$ and exd/Ubx regulation.

Protein-protein interactions have been described to enhance the specificity, and/or to regulate the function, of several classes of homeo domain-containing proteins. The yeast MAT $\alpha 1$ and MAT $\alpha 2$ transcription factors make protein-protein contacts with a cofactor (MCM1) that influences their ability to discriminate between different targets (Smith and Johnson 1992). Interestingly, interaction between $\alpha 2$ and MCM1 is mediated by the flexible extension of the $\alpha 2$ homeo domain (Vershon and Johnson 1993). This region contains sequences related to the YPWM motif conserved upstream of all Hox homeo domains belonging to the paralogous groups 1-8 (see Mavilio 1993), although our data indicate that this motif is not sufficient per se to mediate protein-protein contacts, at least in the case of two interacting Hox proteins. The Drosophila POU domain-containing transcription factor Cf1-a can establish high-affinity heterodimeric interaction with a second POU protein, I-POU, which is unable to bind DNA but can prevent Cfl-a from binding to its target. The heterodimeric interaction between the two factors is specifically mediated by the amino-terminal part of the I-POU homeo domain (Treacy et al. 1991, 1992). It seems therefore likely that the amino-terminal region of different types of homeo domain share the conserved function of mediating selective protein-protein interactions, which might be an essential requirement for regulating their specificity of action as activators, coactivators, or repressors. Our data extend this function to the amino terminus of the homeo domain of the Hox proteins, which were not yet reported to establish, and be functionally regulated by, protein-protein interactions. The Hox homeo domain is potentially able to establish interactions with a number of different partners, as HOXD8 can interact with at least six HOX proteins belonging to at least three different clusters and five paralogous groups.

\section{Amino-terminal effector domains are required for the function of Hox proteins}

The amino terminus/helix 1 region of the HOXD8 homeo domain, although necessary, is not sufficient for

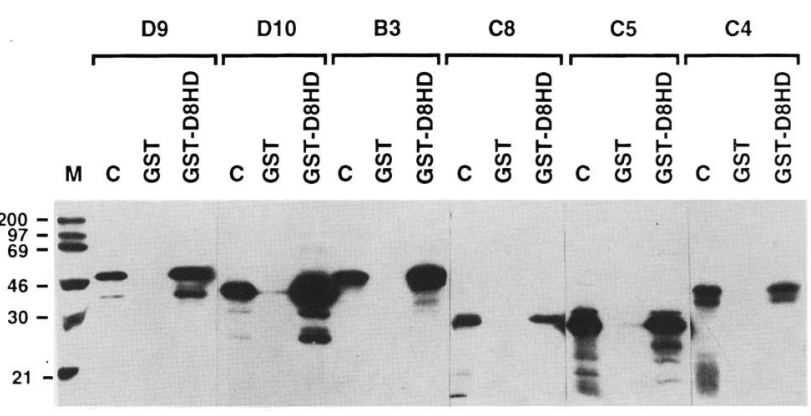

Figure 9. Protein-protein interaction in solution between the HOXD8 homeo domain and six members of the HOX gene family belonging to different clusters and paralogous groups. The GST-D8HD resin (see Fig. 5) was batch-adsorbed to ${ }^{35} \mathrm{~S}$-labeled HOXD9 (D9), HOXD10 (D10), HOXB3 (B3), HOXC8 (C8), HOXC5 (C5), and HOXC4 (C4) proteins, and then analyzed by SDS-PAGE. 
inhibition of the HOXD9 activity on HCR, which requires the presence of a second (in turn) nonsufficient domain consisting of the amino-terminal 46 residues. We interpret these findings by proposing that the negative activity of HOXD8 requires the combined presence of a protein-protein interaction function, located in the homeo domain, and an effector function, located in the amino terminus (see model in Fig 10). The former does not necessarily require HOXD8-specific sequences, as it can be exerted also by the corresponding, nonidentical region of $\mathrm{HOXD9}$, whereas the latter is specifically encoded in the HOXD8 amino terminus. The amino-terminal end is extremely conserved among Hox proteins belonging to the paralogous group 8 (see Fig. 8). Interestingly, HOXC8 has the same negative activity of HOXD8 in our system, whereas the product of the mouse Hoxb-8 gene was reported to inhibit the activating function of $H o x b-9$ on the N-CAM promoter, a putative Hox gene target (Jones et al. 1992). Inhibition of Hox gene function seems therefore to be a common characteristics of Hox proteins belonging to the paralogous group 8 .

The activating function of HOXD8 on the appropriate target is also mediated by an effector domain, located somewhere between residues 46 and 117 in the protein amino terminus. This region, relatively less conserved among paralogous genes, can be replaced by a different activator domain, such as the yeast GAL4 acidic activator, but not by a nonspecific polypeptide of comparable size. An intact amino-terminal domain is necessary for the activating function of HOXD9 as well. These results show that positive and negative transcriptional activity of HOX proteins are mediated by specific effector domains located in the amino terminus.

Based on our data, a model can be therefore proposed in which a general, protein-protein contact interface can be utilized to mediate combinatorial and/or hierarchical functional relationships among Hox gene products, the function of which is exerted by effector domains localized in different, specific regions of the proteins. The biochemical nature of these effector functions is unknown, although it may conceivably involve interactions with effector domains of other Hox proteins, and/ or with other still unidentified components of the transcriptional machinery. It will be of interest to test whether these multiple interactions are functionally significant in the translation of the Hox "code" into positional specification in developing embryos.

\section{Materials and methods}

\section{Protein expression and reporter plasmids}

The pD9 and pD8 expression constructs (no. 1 in Fig. 1) were generated by cloning the complete open reading frame of the HOXD9 and HOXD8 cDNAs (Izpisua-Belmonte et al. 1990; Zappavigna et al. 1991) into the BamHI site of the pSG5 expression vector (Green et al. 1988). The pGALD8 construct (no. 3) was generated by cloning an EcoRI-BamHI fragment containing the yeast GAL4 activation domain (amino acids 149-196) fused
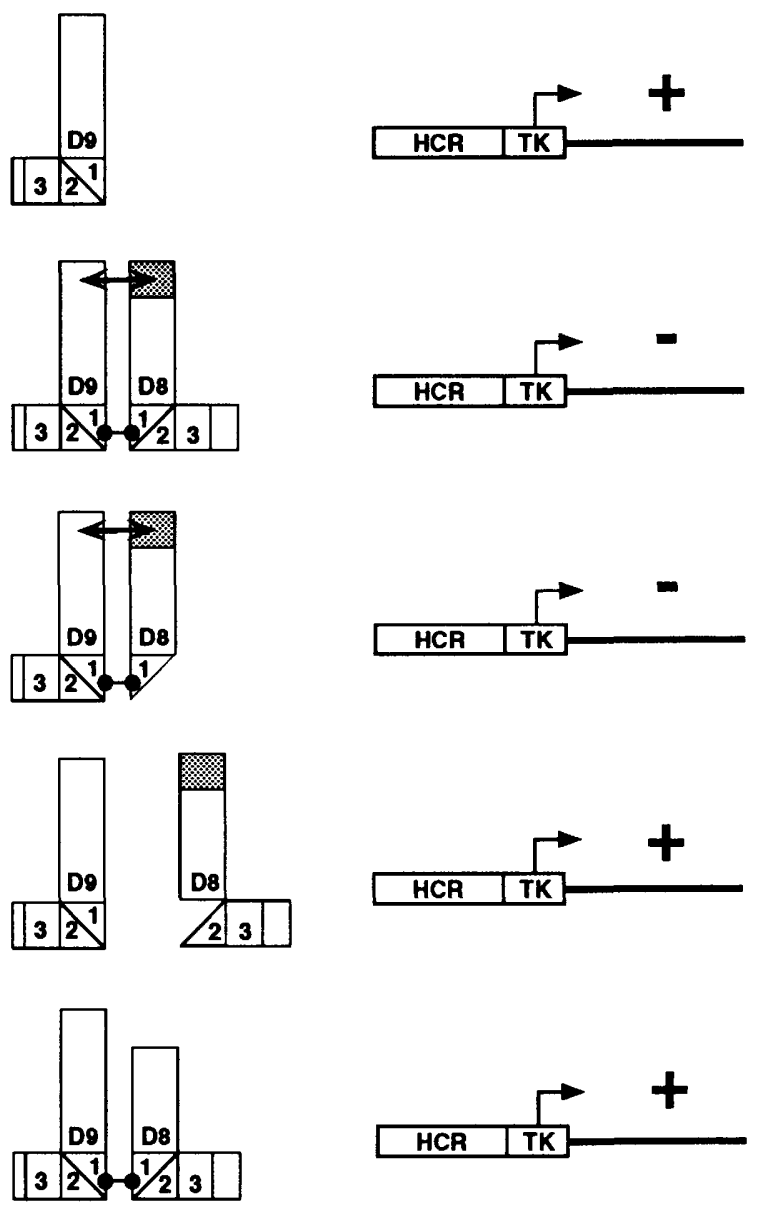

Figure 10. Summary of the HOXD8/HOXD9 interactions on the HCR target. Proteins expressed by some of the expression constructs shown in Fig. 1 are schematically represented by L-shaped assemblies of separate domains (boxes), i.e., the HOXD9 (D9) and HOXD8 (D8) amino-terminal regions, the homeo domain amino terminus/helix $1(1)$, helix $2(2)$, and helix 3-4 $\langle 3\rangle$, and the carboxy-terminal regions. (Stippled box) HOXD8 negative effector domain. The effect of each combination of expressed proteins on the transcription of the cotransfected pTHCR target is indicated by a + (activation) or a (inhibited activation) sign. The homeo domain amino terminus/helix 1, and the amino-terminal effector domain are both necessary for the HOXD8 negative activity on HOXD9. Deletion mutants lacking either domain have no inhibitory effect. In this model, the homeo domain amino terminus/helix 1 provides a protein-protein contact interface with the corresponding region of HOXD9 and/or other unidentified cofactors /indicated by two dots linked by a bar), whereas the effector domain exerts the negative activity by interacting with the HOXD9 protein and/or other components of the transcriptional machinery (indicated by a bidirectional arrow).

to a BamHI-EcoRI fragment containing the homeo domain and carboxyl terminus of HOXD8 into the EcoRI site of pSG5.

Expression vectors for the truncated forms of HOXD8, and the hybrid HOXD8/HOXD9 proteins, were constructed as follows: (No. 4) pD8swD9 was generated by ligating a Asp718 (Klenow-filled-EagI, PCR-amplified fragment containing the HOXD9 homeo box to a SacI-AccI (Klenow-filled) fragment encoding the HOXD8 amino terminus and to a SacI-EagI fragment 
encoding the HOXD8 carboxyl terminus. The resulting construct codes for a protein containing amino acids 1-193 of HOXD8 followed by amino acids 274-339 of HOXD9 and amino acids 260-289 of HOXD8. (No. 5) pD9swD8 was constructed by ligating a PCR-generated fragment containing the HOXD8 homeo box fused to the 3-amino acid HOXD9 carboxyl terminus to the BamHI site $5^{\prime}$ to the homeo box in the HOXD9coding region. (No. 6) pD8H1D9 was constructed by fusing a pD8swD9-derived EcoRI fragment encoding the HOXD8 amino terminus and the HOXD9 homeo domain amino terminus/helix 1 to an EcoRI fragment encoding the HOXD8 homeo domain helix 2-4 and carboxyl terminus. (No. 7) pD8 $\mathrm{H}$ H2/3 (representing a deletion of amino aicds 215-289) was obtained by recloning in pSG5 a pD8 EcoRI fragment extending from a site $5^{\prime}$ to the ATG codon to a site at position +637 from the ATG in the HOXD8 coding sequence (Izpisua-Belmonte et al. 1990). A stop codon (TAA) located 16-bp 3' from the EcoRI site in pSG5 was thereby put in-frame into the deleted HOXD8 protein. (No. 8) pD8HD was generated by digestion at two SacI sites located at position +3 and +520 , resulting in an in-frame internal deletion of amino acids 2-176. (No. 9) pD8 $\Delta \mathrm{HD}$ was generated by cutting the HOXD8-coding sequence at an AccI site located 5' to the HOXD8 homeo box, resulting in a deletion of amino acids 195-289. (No. 10) pD8 $\Delta \mathrm{Hl}$ (internal deletion of amino acids 196-214) was generated by ligation of an AccI-BamHI-digested, PCR-generated fragment containing the homeo domain second and third helices and the carboxyl terminus of the HOXD8 protein to an EcoRI-AccI fragment encoding the amino terminus of the HOXD8 protein. pD9swD8H1 (no. 11) pD8swD9H1 (no. 12) were derived from the corresponding full-length constructs by recloning the amino-terminal EcoRI fragments in pSG5, as described for $\mathrm{pD} 8 \Delta \mathrm{H} 2 / 3$. (No. 13) pGSTD8H1 was generated by cloning an EcoRI-BamHI-digested, PCR-amplified fragment containing the complete coding region of the GST gene fused to the amino terminus/helix 1 of HOXD8, into the EcoRI and BamHI sites of pSG5. (No. 14) pD8ARP1 (internal deletion of amino acids 15-33) was obtained by deletion of nucleotides +43 to +100 through PCR splicing by overlap extension. (No. 15) pD8 $\Delta \mathrm{RP2} / 3$ (internal deletion of amino acids 67-79 and 106-120) was similarly constructed by deleting nucleotides +198 to +268 and +316 to +378 . (No. 16) pD8 $(1-117)$ was constructed by cutting the HOXD8-coding sequence at the SmaI site at position +255 . The $\mathrm{D} 8 \Delta(1-117)$ protein was translated starting from the ATG codon at position +352 . (No. 17) $\mathrm{pD} 8 \Delta(1-46)$ was generated by cutting the $\mathrm{pD} 8$ construct at a Sacl site $3^{\prime}$ to the ATG codon, and ligating it to a NotI-BglII fragment encoding amino acids 46-289 of the HOXD8 protein. (No. 18) pD8NTD9 was obtained by cloning into pSG5 a PCRamplified EcoRI-NotI fragment encoding the HOXD9 amino terminus (amino acids 1-46) and a NotI-BgIII fragment from pD8 encoding amino acids 47-289 of HOXD8. All constructions including PCR-amplified regions were controlled by DNA sequencing.

Production and nuclear localization of proteins produced by expression constructs containing partial HOXD8 sequences were tested by immunofluorescence and immunoblotting on transfected NIH-3T3 cells using a series of monoclonal antibodies directed against the amino terminus or the homeo domain of HOXD8 (V. Zappavigna et al., in prep.), and either a goat anti-mouse fluorescein-conjugated secondary antibody (Coulter Immunology, Hialeah, FL) or ${ }^{125}$ I-labeled protein A.

pTHCR was constructed as reported previously (Zappavigna et al. 1991). pTCBS was generated by cloning a eightfold multimerized form of the oligonucleotide 5'-TCGAGTCATCTCAATTAGCGCAGTCGA-3' into the SalI and XhoI sites of the pT109luc luciferase reporter vector (Nordeen 1988).
Cell culture, transfection, and luciferase assay

NIH-3T3 cells were maintained in Dulbecco's modified eagle's medium (DMEM) supplemented with $10 \%$ fetal calf serum (GIBCO). Transfections were carried out by standard calciumphosphate precipitation using $10 \mu \mathrm{g}$ of reporter plasmid, $5 \mu \mathrm{g}$ of expression construct, and $1 \mu \mathrm{g}$ of pRSV- $\beta$-gal as an internal control (Bonnerot et al. 1987) per 9-cm dish. Cells were harvested 48-60 hr after transfection, lysed with three cycles of freezing and thawing, and centrifuged at $4^{\circ} \mathrm{C}$ in an Eppendorf microcentrifuge for $15 \mathrm{~min}$. Luciferase and $\beta$-galactosidase assays were carried out as described previously (Zappavigna et al. 1991).

\section{Protein-protein affinity-chromatography}

GST fusion proteins were produced using the pGEX bacterial expression vector system (Pharmacia, Uppsala, Sweden). The pGEXD9HD construct was obtained by cloning a PCR-generated, BamHI-digested fragment containing the HOXD9 homeo domain into the polylinker of the pGEX vector. pGEXD9Hl was generated from pGEXD9HD by cutting/religating at EcoRI sites located within the homeo box and at the $3^{\prime}$ end of the pGEX polylinker. pGEXD8HD was constructed by ligating a BamHI fragment from $\mathrm{pD} 8 \mathrm{HD}$, containing the HOXD8 homeo domain, into the BamHI site of pGEX. pGEXD8H1 was derived from pGEXD8HD by digestion/religation at EcoRI sites located within the homeo box and at the $3^{\prime}$ end of the pGEX polylinker. Bacteria transformed with pGEX constructs were grown in 100 $\mathrm{ml}$ of Luria broth to an OD of $0.3-0.5$, induced with $0.5-1.0 \mathrm{mM}$ IPTG, and harvested after $2 \mathrm{hr}$. Bacterial pellets were resuspended in $500 \mu \mathrm{l}$ of PBS and sonicated. Insoluble material was removed by centrifugation and the supernatant incubated with glutathione-Sepharose $4 \mathrm{~B}$ resin (Pharmacia) for $30 \mathrm{~min}$ at $4^{\circ} \mathrm{C}$ on a rotating wheel. Beads were washed four times with PBS and once with HND buffer ( $20 \mathrm{~mm}$ HEPES at $\mathrm{pH} 7.4,50 \mathrm{~mm} \mathrm{NaCl}$, $0.1 \% \mathrm{NP}-40,5 \mathrm{~mm}$ DTT, $10 \mathrm{mg} / \mathrm{ml}$ of BSA). ${ }^{35} \mathrm{~S}$-Labeled proteins were produced in rabbit reticulocyte lysates (Promega) from RNAs transcribed in vitro from the $\mathrm{T} 7$ promoter present in the pSG5 expression vector. Ten microliters (packed volume) of the resin bearing equal amounts of either GST or the fusion proteins $(\sim 5 \mu \mathrm{g}$, or $0.15 \mathrm{nmoles})$ were batch-adsorbed for $1 \mathrm{hr}$ at $+4^{\circ} \mathrm{C}$ on a rotating wheel to ${ }^{35} \mathrm{~S}$-labeled proteins $\mid \sim 45 \mathrm{ng}$, or 1 pmole) in $200 \mu$ l of HND buffer (final concentrations: $\sim 1 \mu \mathrm{M}$ for the GST fusion proteins and $\sim 5 \mathrm{nM}$ for the labeled proteins). The resin was washed four times in a 100-fold (vol/vol) excess of MTPBS $150 \mathrm{~mm} \mathrm{NaCl}, 16 \mathrm{mM} \mathrm{Na}_{2} \mathrm{HPO}_{4}, 4 \mathrm{~mm} \mathrm{NaH}{ }_{2} \mathrm{PO}_{4}$, $0.1 \% \mathrm{NP}-40$ ), resuspended in Laemmli sample buffer, and analyzed by SDS-PAGE.

\section{DNA-protein binding studies}

A NcoI-BamHI fragment derived from the pTrcHisA bacterial expression vector (Invitrogen), encoding a 35-amino acid region containing a 6-histidine tag, was fused to the amino terminus of the HOXD8 and HOXD9 proteins by ligation into the BamHI site of $\mathrm{pD} 8$ and $\mathrm{pD} 9$, to generate the $\mathrm{pHisD} 8$ and $\mathrm{pHisD} 9 \mathrm{eu}$ karyotic expressor constructs. These plasmids were transfected into NIH-3T3 cells by standard calcium-phosphate precipitation. Cells were harvested after $60 \mathrm{hr}$, nuclear proteins were extracted, and histidine-tagged, native HOXD8 and HOXD9 proteins purified by affinity-chromatography on a $\mathrm{Ni}^{2+}$ nitrilotriacetic acid $\left(\mathrm{Ni}^{2+} \mathrm{NTA}\right.$-agarose resin (Qiagen) according to the manufacturer's specifications.

Binding of purified Hox proteins was analyzed by gel retardation as described previously (Zappavigna et al. 1991). Dissocia- 
tion rate was determined by adding a 250 -fold excess of cold oligonucleotide to the incubation mixture at $0^{\circ} \mathrm{C}$, and loading aliquots on a running $4 \%$ polyacrylamide gel at short time intervals. Gels were dried and exposed to a Kodak XAR film at $-70^{\circ} \mathrm{C}$. The double-stranded oligonucleotide used as probe $\left(5^{\prime}-\right.$ GGGACACATTAATCTATAATCAAATACACCTC-3') corresponded to the $5^{\prime}$ portion of the HCR region (Zappavigna et al. 1991).

\section{Acknowledgments}

This work was supported by grants from the Italian Association for Cancer Research (AIRC), the European Community (Biotechnology Program) and the Italian National Research Council (CNR), Special Projects "Ingegneria Genetica" and "ACRO". Thanks go to Francesca Castagna for help in protein-protein affinity-chromatography experiments, Gilbert Urier for the gift of the pTCBS reporter plasmid, Anne Dejan for the pRARE-TKluc plasmid, Pierre Chambon for the pSGRAR $\beta$ expression vector, and Giovanna Viale for developing the anti-HOXD8 monoclonal antibodies. The expert assistance of Valeria Ganazzoli in typing the manuscript is hereby gratefully acknowledged.

The publication costs of this article were defrayed in part by payment of page charges. This article must therefore be hereby marked "advertisement" in accordance with 18 USC section 1734 solely to indicate this fact.

\section{References}

Ananthan, J., R. Baler, D. Morissey, J. Zuo, Y. Lan, M. Weir, and R. Voellmy. 1993. Synergistic activation of transcription is mediated by the amino-terminal domain of Drosophila fushi tarazu Homeoprotein and can occur without DNA binding by the protein. Mol. Cell. Biol. 13: 1599-1609.

Arcioni, L., A. Simeone, S. Guazzi, V. Zappavigna, E. Boncinelli, and F. Mavilio. 1992. The upstream region of the human homeobox gene HOX3D is a target for regulation by retinoic acid and HOX homeoproteins. EMBO J. 11: 265-277.

Bonnerot, C., D. Rocancourt, P. Briand, G. Grimbier, and J. Nicolas. 1987. A $\beta$-galactosidase hybrid protein targeted to nuclei as a marker for developmental studies. Proc. Natl. Acad. Sci. 84: 6795-6799.

Desplan, C., J. Theis, and P.H. O'Farrell. 1988. The sequence specificity of homeodomain-DNA interaction. Cell 54: 1081-1090.

Duboule, D. 1992. The vertebrate limb: A model system to study the $H o x / H O M$ gene network during development and evolution. BioEssays 14: 375-384.

Fainsod, A., L.D. Bogard, T. Ruusala, M. Lubin, D.M. Crothers, and F.H. Ruddle. 1986. The homeodomain of a murine protein binds $5^{\prime}$ to its own homeobox. Proc. Natl. Acad. Sci. 83: 9532-9536.

Fitzpatrick, V.D., A. Percival-Smith, C.J. Ingles, and H.M. Krause. 1992. Homeodomain-independent activity of the fushi tarazu polypeptide in Drosophila embryos. Nature 356: $610-612$.

Furukubo-Tokunaga, K., S. Flister, and W.J. Gehring. 1993. Functional specificity of the Antennapedia homeodomain. Proc. Natl. Acad. Sci. 90: 6360-6364.

Gehring, W.J., M. Müller, M. Affolter, A. Percival-Smith, M. Billeter, Y.Q. Qian, G. Otting, and K.Wüthrich. 1990. The structure of the homeodomain and its functional implications. Trends Genet. 6: 323-329.

Gill, G. and M. Ptashne. 1987. Mutants of GAL4 protein altered in an activation function. Cell 51: 121-126.
Green, S., I. Issemann, and E. Sheer. 1988. A versatile eucaryotic expression vector for protein engineering. Nucleic Acids Res. 16: 369-373.

Gruss, P. and M. Kessel. 1991. Axial specification in higher vertebrates. Curr. Opin. Genet. Dev. 1: 204-210.

Han, K., M.S. Levine, and J.L. Manley. 1989. Synergistic activation and repression of transcription by Drosophila homeobox proteins. Cell 56: 573-583.

Hayashi, S. and M. Scott. 1990. What determines the specificity of action of Drosophila homeodomain proteins? Cell 63: $883-894$.

Hoey, T. and M. Levine. 1988. Divergent homeobox proteins recognize similar DNA sequences in Drosophila. Nature 332: 858-861.

Hunt, P. and R. Krumlauf. 1991. Deciphering the Hox code: Clues to patterning branchial regions of the head. Cell 66: $1075-1078$.

Izpisua-Belmonte, J.-C., P. Dollé, A. Renucci, V. Zappavigna, H. Falkenstein, and D. Duboule. 1990. Primary structure and embryonic expression pattern of the mouse Hox-4.3 homeobox gene. Development 110: 733-746.

Jaynes, J.B. and P.H. O'Farrell. 1988. Activation and repression of transcription by homeodomain-containing proteins that bind a common site. Nature 336: 744-749.

- 1991. Active repression of transcription by the Engrailed homeodomain protein. EMBO $/$. 10: 1427-1433.

Jones, F.S., E.A. Prediger, D.A. Bittner, E.M. De Robertis, and G.M. Edelman. 1992. Cell adhesion molecules as targets for Hox genes: Neural cell adhesion molecule promoter activity is modulated by cotransfection with Hox-2.5 and -2.4. Proc. Natl. Acad. Sci. 89: 2086-2090.

Jones, F.S., B.D. Holst, O. Minowa, E.M. De Robertis, and G.M. Edelman. 1993. Binding and transcriptional activation of the promoter for the neural cell adhesion molecule by HoxC6 (Hox-3.3). Proc. Natl. Acad. Sci. 90: 6557-6561.

Kessel, M. and P. Gruss. 1991. Homeotic transformations of Murine vertebrae and concomitant alteration of Hox codes induced by retinoic acid. Cell 67: 89-104.

Krumlauf, R. 1993. Hox genes and pattern formation in the branchial region of the vertebrate head. Trends Genet. 9: 106-112.

Kuziora, M.A. and W. McGinnis. 1989. A homeodomain substitution changes the regulatory specificity of the Deformed protein in Drosophila embryos. Cell 59: 563-571.

- 1991. Altering the regulatory targets of the Deformed protein in Drosophila embryos by substituting the Abdominal-B homeodomain. Mech. Dev. 33: 83-94.

Laughon, A. and M.P. Scott. 1984. Sequence of a Drosophila segmentation gene: Protein structure homology with DNAbinding proteins. Nature 310: 25-31.

Le Mouellic, H., H. Condamine, and P. Brùlet. 1988. Pattern of transcription of the homeo-gene Hox-3.1 in the mouse embryo. Genes \& Dev. 2: 125-135.

Lin, L. and W. McGinnis. 1992. Mapping functional specificity in the Dfd and Ubx homeo domains. Genes \& Dev. 6: 10711081.

Manak, J.R. and M.P. Scott. 1993. Able assistants for homeodomain proteins. Curr. Biol. 3 318-320.

Mavilio, F. 1993. Regulation of vertebrate homeobox-containing genes by morphogenes. Eur. J. Biochem. 212: 273-288.

McGinnis, W. and R. Krumlauf. 1992. Homeobox genes and axial patterning. Cell 68: 283-302.

Müller, M., M. Affolter, W. Leupin, G. Otting, K. Wühtrich, and W.J. Gehring. 1988. Isolation and sequence specific binding of the Antennapedia homeodomain. EMBO I. 7: 4299-4304.

Nordeen, S.K. 1988. Luciferase reporter gene vectors for analysis 
of promoters and enhancers. BioTechniques 6: 454-457.

Odenwald, W.F., J. Garbern, H. Arnheiter, E. Tournier-Lasserve, and R.A. Lazzarini. 1989. The Hox-1.3 homeo box protein is a sequence-specific DNA-binding phosphoprotein. Genes \& Dev. 3: 158-172.

Peifer, M. and E. Wieschaus. 1990. Mutation in the Drosophila gene extradenticle affect the way specific homeo domain proteins regulate segmental identity. Genes \& Dev. 4: 12091223.

Pöpperl, H. and M.S. Featherstone. 1992. An autoregulatory element of the murine Hox-4.2 gene. EMBO J. 11: 3673-3680.

Rauskolb, C., M. Pfeifer, and E. Wieschaus. 1993. extrandenticle, a regulator of homeotic gene activity, is a homolog of the Homeobox-containing human proto-oncogene $p b \times 1$. Cell 74: $1101-1112$.

Sasaki, H., E. Yokoyama, and A. Kuroiwa. 1990. Specific DNAbinding of the two chicken Deformed family homeodomain proteins, Chox-1.4 and Chox-a. Nucleic Acids Res. 18: $1739-1747$.

Schier, A.F. and W.J. Gehring. 1993. Functional specificity of the homeodomain protein fushi tarazu: The role of DNAbinding specificity in vivo. Proc. Natl. Acad. Sci. 790: 14501454.

Schubert, F.R., K. Nieselt-Struwe, and P. Gruss. 1993. The Antennapedia-type homeobox genes have evolved from three precursors separated early in metazoan evolution. Proc. Natl. Acad. Sci. 90: 143-147.

Smith, D.L. and A.D. Johnson. 1992. A molecular mechanism for combinatorial control in yeast: MCM1 protein sets the spacing and orientation of the homeodomains of an $\alpha 2$ dimer. Cell 68: 133-142.

Stern, S., M. Tanaka, and W. Herr. 1989. The Oct-1 Homeodomain directs formation of a multiprotein-DNA complex with the HSV transactivator VP16. Nature 341: 624.

Treacy, M.N., X. He, and M.G. Rosenfeld. 1991. I-POU: A POU domain protein that inhibits neuron-specific gene activation. Nature 350: 577-584.

Treacy, M.N., L.I. Neilson, E.E. Turner, X. He, and M.G. Rosenfeld. 1992. Twin of I-POU: A two amino acid difference in the I-pou homeodomain distinguishes an activator from an inhibitor of transcription. Cell 68: 491-505.

Verrijzer, C.P., J.A.W.M. van Oosterhout, and P.C. van der Vliet. 1992. The Oct-1 POU domain mediates interactions between Oct-1 and other POU proteins. Mol. Cell. Biol. 12: $542-551$.

Vershon, A.K. and A.D. Johnson. 1993. A short disordered protein region mediates interactions between the homeodomain of the yeast $\alpha 2$ protein and the MCM1 protein. Cell 72: 105-112.

Zappavigna, V., A. Renucci, J.C. Izpisua-Belmonte, G. Urier, C. Peschle, and D. Duboule. 1991. HOX4 genes encode transcription factors with potential auto- and cross-regulatory capacities. EMBO I. 10: 4177-4187. 


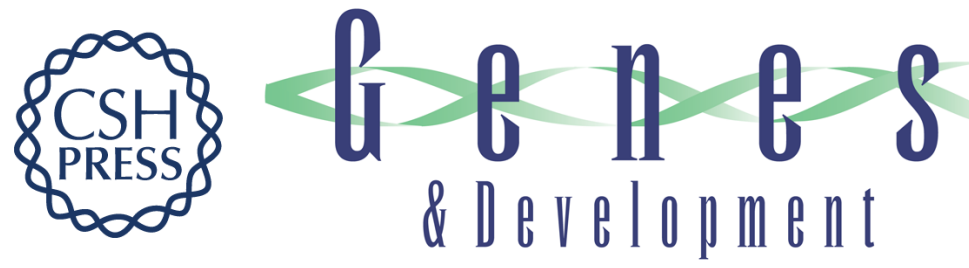

\section{Specificity of HOX protein function depends on DNA-protein and protein-protein interactions, both mediated by the homeo domain.}

V Zappavigna, D Sartori and F Mavilio

Genes Dev. 1994, 8:

Access the most recent version at doi:10.1101/gad.8.6.732

References This article cites 46 articles, 12 of which can be accessed free at:

http://genesdev.cshlp.org/content/8/6/732.full.html\#ref-list-1

License

Email Alerting

Service

Receive free email alerts when new articles cite this article - sign up in the box at the top right corner of the article or click here.

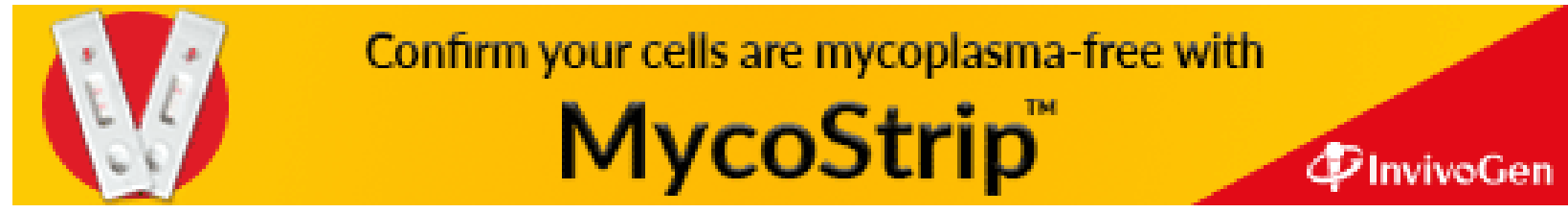

